\title{
JOB STRESS AND ITS INFLUENCE ON THE DOCTOR'S PERFORMANCE IN THE PUBLIC HOSPITAL OF PESHAWAR CITY, PAKISTAN
}

\author{
Waseeq Ullah', Syeda Farhana Jabeen Shah', Waqar Ahmad² \\ 2. Kabir Medical College \\ 3. Khyber Medical College
}

\begin{abstract}
The study aims to find the influence of the job stress on the doctor's performance in the public hospitals of Peshawar city. No doubt the profession of doctors is very respectable and they are doing a good work serving the people of society but their work environment must have some sort of influence on their performance as well. That's why this study was taken in to consideration to study the doctors' performance in the public hospitals. This study was designed to assess the doctor's performance in public hospitals only. Sample size was drawn on the basis of simple random sampling technique as the data was of quantitative in nature. Data was collected through a questionnaire which was developed by the research himself and to find the reliability and validity a pilot test was done with the data collection tool which showed some mistakes and those mistakes were rectified. Due to limited time period and resources of the researcher, the researcher has drawn 150 sample size of the total population of the doctors in the public hospitals of Peshawar city. A total of 150samples (50 from each public hospitals respectively of Peshawar) data were collected .Out of 150 study participants; it was observed that doctors in KTH, LRH and HMC were suffering from job stress collectively. Their performance was affected and the result of this study highlight the significant result in which it was concluded that job stress had a negative impact on the doctor's performance in the public hospitals of Peshawar.
\end{abstract}

\section{KEYWORDS}

Job Stress, Public Hospitals, Doctor's performance, KTH, LRH and HMC

\section{INTRODUCTION}

The term stress refers to a condition in which an individual is not able to meet the demands which are expected from him with the present resources available to him. Although still there is an

\begin{tabular}{c} 
Correspondence: \\
Dr. Waseeq Ullah \\
Kabir Medical College \\
Contact: 0300-9087709 \\
Email: dr.waseeq091@gmail.com \\
\hline
\end{tabular}
argument found among researchers when it comes to define stress, as stress has various definition due to various fields of study and every field has its own definition1.On the other hand stress is also defined as a phenomenon which can be either primary or secondary that bring about a misbalance within an individual2. Further he added to the definition that it is a voluntary response made to the phenomenon that has brought a change in the individual's normal state.

Similarly stress has been defined as a process of reaction that occurs when an individual's demand collides with its environment 3,4 . On the other hand it is further added to the definition that it is a phenomenon but it involves the person response to its environment, only when the individual is not able to fulfill the demand of the environment, Such demands can be primary and secondary that bring about a change in the person's state and leading him to suffer from a state of disturbance and such person is unable to perform normal like others in the surroundings 5,6 .It has been observed for past so many years that people are suffering from stress when they come across an opportunity or problem that disturb their mental and behavioral capabilities. They are unable to cope up with others and their performance is not up to the expectation of the organization and the people who are living in near surrounding to him 7. It was the year of 1936 that stress was formally introduced as an issue that was affecting the employee's performance in various social fields of life. It was observed that it was one of the major reason that employees 
were not able to cope with it and their performance below the expectation of the organization where they were working 7 . Some studies have revealed that stress has not always bad impression on anybody's work but it has sometimes brought good result because it creates pressure in an individual mind and he or she then start working hard to fulfill his or her set goal. In this way it is not appropriate to say that stress has come up with negative result always 8 . This thesis will focus on the issue of job stress and its influence on the doctor's performance in the public hospitals of Peshawar, Pakistan. Such important report will open the doors to new knowledge and add more to the available knowledge which were made by other researchers I the same or related field. This report will help in finding the main points which can be reduced or increased in order to improve the doctor's daily performance. "Job stress and its influence on the doctor's performance in the public hospitals of Peshawar city, Pakistan". The aim of the study is to explore the relative influence of the job stress through which doctor go and how this stress has affected their daily performance. Doctors have to do a lot of work when in hospital and that's why this study finds that how their performance gets affected by the routine stress. The main objective is: To examine whether jib stress has any positive or negative influence on doctor daily performance in the public hospitals of Peshawar city, Pakistan.

This report will cover only the public hospitals which are operating in Peshawar city. Public hospitals are situated in Hayatabad, university town and city side. Therefore these three public hospitals will become a part of this thesis. Public hospitals are governed by the Government of Khyber Pakhtunkhwa province. This report will cover the doctors who are working in these hospitals. The scope will cover only these three public hospitals in Peshawar. Doctors are very professional and committed people to their job. They not only do their job just for the sake of their duty but they do social work by dealing with ill and injured people. Their work needs to be very appreciated as compared to other professions. This study is focused on the doctors of public hospitals, where there is more hectic task as compared to other private hospitals. This report will explain the influence of the stress through which every doctor goes. But this is not all. This thesis will check that either this influence has any positive or negative effect on doctor's daily performance. This report is very important in this regard. Doctor's profession is much more complex and such study will further give importance to their day to day duties and a better understanding to improve their performance.

Previous reports have shown that medical profession is very complex and very hectic as it involves dealing with ill and injured people, their interaction is more with patients and the social life is limited to their immediate family members only 5 . The public hospitals are not that facilitated as the private hospitals are in the Peshawar, as it can be simply observed when evaluating the hospitals by an individual. In this situation it can be observed that middle class and lower class people visit more to public hospital than private hospitals in Peshawar. This study will try to check whether the job stress faced by the doctors in the public hospitals have any positive or negative effect on their daily performance. Doctor is such a professional whose performance matters a lot and their one mistake can risk anybody's life. Therefore doctors need to be in better position here they can perform well. This study will observe that job stress in public hospital affects the doctors in which aspect. This attaches more rationale to this topic in this regard.

The study has taken tow variables that will be the center of focus all the way till the completion of report. Those variables are:

INDEPENDENT VARAIBLE DEPENDANT VARIABLE

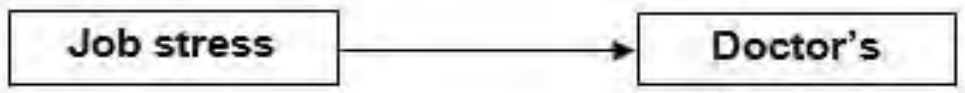


Hypothesis:

H1: There is negative impact of the job stress on the doctor's performance in the public hospitals.

H0: There is positive impact of the job stress on the doctor's performance in the public hospitals.

The only problem, which was faced by the researcher, was that it was hard to take time from the doctors when they were in hospital. They were extremely busy dealing with their patients and this took a lot time of the researcher in gathering the data from them through filling the questionnaire. Many occupations have been observed in the present with a lot of employees suffering from job or work stress at their respective organization. This has been proven by a number of researches done all over the world in various field of life and it has further added their respective impact on the professional and social life. There always some reason behind this tension that causes severe stress among employees. Every field of profession has its own causes and some are similar to others and some are different to other professions. It has been observed that sometimes stress has positive and progressive improvement in the performance of workers and sometimes they have been showing not good result at their work place 9 .

In the field of engineering it has been observed that people working at the organization have shown severe job stress that have been caused due to relation of employers and the employees with the worker and this have brought a great negative shift in the performance of the engineers. Such studies that were conducted in the America, Malaysia and South Africa proved that stress is not good sign for the performance of employees. They should try to avoid the causes that results in the development of feelings of stress in them. The management of the organization needs to improve the working condition and try to eliminate those factors that are the sole reason behind it 10. In the field of teaching it has been observed that people working at the organization have shown severe job stress that have been caused due to relation of colleagues and this has brought a great negative shift in the performance of the teachers and the respective faculty. Such studies that were conducted in the America, Malaysia and South Africa proved that stress is not good sign for the performance of employees. The management of the colleges and universities carried much training to educate the faculty and try to solve their issues among each other and the management but job stress is something that cannot be completely eliminated but it was observed that severity of the stress was reduced due to corrective actions taken by the management. They should try to avoid the causes that results in the development of feelings of stress in them. The management of the organization needs to improve the working condition and try to eliminate those factors that are the sole reason behind it 11 . On the other hand it was observed that such stress has brought positive impact in those universities which were offering business administration studies to student in North American universities. This job stress triggered the will in the teachers to work hard and to compete with others and to improve their performance 12.

It has been observed that doctors working at the public hospitals have shown severe job stress that have been caused due to hectic activities and the job complexity and this has brought a great negative shift in the performance of the doctors and the respective medicine filed in the public hospitals. Such studies that were conducted in the Brazil proved that stress is not good sign for the performance of doctors. They should try to avoid the causes that results in the development of feelings of stress in them. The management of the hospitals needs to improve the working condition and try to eliminate those factors that are the sole reason behind it. The management of the hospital needs to divide the work burden on every doctor equally and their respective wards or department. It was also seen the doctors who were suffering from job stress they were found smoking and drinking excessively. They used these habits to reduce the work load and get rid of the job stress. 13. 
On the other hand it has been observed that people working at the private hospitals have shown little job stress that have been caused due to death and dealing with ill and helpless people and this has brought a no change in the performance of the doctors. Such studies that were conducted in the Dubai proved that stress has no relation with performance of doctors at hospitals in Dubai. Although the doctors and the management of the private hospitals were of the view that stress is not good for their doctors as it may deviate their concentration and the quality of the work of their doctors. They try to avoid the causes that results in the development of feelings of stress in them. The management of the hospitals was very focused on the improvement of every factor which may in future result in the work or job stress among their employees 14 . On the other hand it was further observed that stress as more observed in the males than in the female doctors working in the private hospitals of Dubai. The stress found was not that much affective which can influence the work quality of the doctors but still the management of was of the view that they try their level best to control the quality of the work of their doctors by providing them different incentives and ways through which they can reduce their stress level 15.

In the medical universities it has been observed that people studying medicines in medical universities in U.K have shown severe stress that have been caused due to the load of studies, studying environment which is very competitive and relation of teachers have with their students which is very demanding that each student should become a good medical practitioner in future has brought a great positive shift in the performance of the students of medicines. Such studies that were conducted in the U.S.A medical universities proved that stress is good sign for the performance of medical students. They should try to promote the causes that result in the development of feelings of stress in them. The management of the medical universities needs to improve the working condition and try to encourage those factors that motivate stress in students and develop the feelings of competition and working hard in their studies. They will prove to be good doctors in the future 16. On the other hand it was observed that such stress has brought negative impact in those universities which were offering social science as course for studies to student in U.S.A universities 17.It has been observed that doctors who were suffering from severe stress that was a result of the job hectic activities and issues like work life balance, such doctors were facing problem with their families as they were unable to give time to their families at home and their life was not on routine tract. Their families had complaint about their husbands and wife that they dint give much to their spouse at home and that's why tensions were arising among the families that resulted in the stress within the doctors practicing medicines at India. Furthermore it was observe that there other causes as well behind such stress which the doctors were feeling and it negatively impacted their performance at the hospitals. Such doctors were not taking interest in their patients and they were found not taking interest in their own wellbeing and the wellbeing of their patient which were under their observation. Sometimes patients have launched complaint against such doctors to the management of the hospitals. Such doctors were also found to be very alcoholic and smokers. Such doctors have conflicts with other colleagues at hospitals and the patients over small issues. In short doctors in Indian hospitals were found that they were suffering from stress which had a negative impact on their performance 18.

The above conclusion from different researcher conducted all over the world has given mix idea about the influence of job stress on the performance of employees. Some say that it has negative relation or negative impact on the performance of employees. Some researchers are of the view that it has positive impact on the performance of doctors and eventually some studies are of the view that it has no impact on the performance of doctors at all. There was one thing common in all the studies that they confirmed that job stress did exist in all type of profession and organization. This study has been taken up for the purpose of finding the impact of job stress on the doctor's performance of public hospitals in Peshawar city of Pakistan. 


\section{METHODOLOGY}

The methodology of this report involves the following variables that need to be taken in consideration on the basis of their importance. The topic is a current hot issue that needs to be addressed in a serious manner. This study cannot be completed without a proper methodology which can assure the accuracy of the data. There is no ready made available data which can be used to make a decision regarding the current topic of the thesis. Therefore the researcher has to investigate the problem by making available fresh primary data. Doctors working in public hospitals all over Pakistan represent the population for this thesis. Thinking of sample size it is better the more doctors can become the participant to this study, the better picture of the problem can be observed. The problem is that the researcher has not available resources that can cover every doctor in the public hospitals of Peshawar. Therefore the sample size was kept 150 that can be easily achieved by the researcher to draw an effective conclusion relevant to the study. The scope will cover three public hospitals so each hospital will provide data of 50 doctors from their different department especially from the emergency department of the hospital which is always busy and the patient visit are more there than to any other section of the hospital. The thesis has to investigate the influence of job stress on the doctor's performance so therefore the researcher will go for the selection of probability (quantitative) techniques; the best technique relevant to this study is the simple random sampling which will give the chance to the researcher to select doctors available to him randomly from the entire hospital.

It is discussed that the researcher has no access to any secondary or available data which can be used for this report. The researcher will have to come up with primary data for the assessment of this report. Although secondary source will be made available to study various article for the literature section of this thesis. Due to limited time available to the researcher and the time available by the doctor to the researcher is less. Therefore conducting an interview session will not be possible to conduct this thesis. Therefore it the best option is to collect the data from the doctor through a questionnaire, which is to be developed by the researcher and then distribute it among the doctors. Although filling questionnaires still requires time but the researcher try his level best to cover the data collection within the specified time period from the doctors as doctors are very busy when they are in hospital. Once the researcher is able to develop a data collection questionnaire , he will check its authenticity by conducting a pilot testing survey and check whether these questions are made correctly and are they able to collect the data which is required by this thesis. Such testing will point out the errors in the questionnaire. This testing will further improve the quality of the questionnaire. This report will require almost two months to be completed. The report will use these two months for starting the thesis from the scratch and complete to the last chapter of the assignment. Calculating the tasks and their related time period it can be assumed that the researcher estimates that the whole thesis report will take almost tow whole months for the completion. The researcher has assigned three weeks to the collection of data from the three public hospitals in Peshawar. The researcher has plan of allocating one week to each hospital completely for data collection. It has been discussed above that the researcher is planning to conduct his study in the public hospitals. Therefore only those doctors will be participant to this assignment who is currently working in the public hospitals of Peshawar. These hospitals are mention in the scope of this assignment. The researcher has already mentioned that his interest is to find the relative influence of jobs tress on the doctor performance in the public hospitals, so the researcher will analyze the data with the help of linear regression test that will give the result that either the impact is positive or negative. 


\section{RESULTS}

Model Summary(Linear Regression Test)

\begin{tabular}{|l|l|l|l|l|}
\hline Model & $\mathbf{R}$ & $\mathbf{R}$ Square & Adjusted R Square & Std. Error of the Estimate \\
\hline 1 & $.694^{\mathrm{a}}$ & .482 & .479 & .635 \\
\hline
\end{tabular}

a. Predictors: (Constant) Job Stress

The value of $R$ shows that 69.4 percent change in doctors performance is due to job stress in public hospitals.

ANOVA
\begin{tabular}{|ll|l|l|l|l|l|}
\hline Model & & Sum of Squares & df & Mean Square & F & Sig. \\
\hline 1 & Regression & 55.626 & 1 & 55.626 & 379.882 & $.000^{a}$ \\
& Residual & 59.708 & 148 & .403 & & \\
& Total & 115.333 & 149 & & & \\
\hline
\end{tabular}

a. Predictors: (Constant) Job Stress

b. Dependent Variable: Doctors performance

The $\mathrm{F}$ value shows that validity and the value got is near or almost 4 which it's showing that it's more valid.

Coefficients

\begin{tabular}{|c|c|c|c|c|c|c|}
\hline \multirow{2}{*}{\multicolumn{2}{|c|}{ Model }} & \multicolumn{2}{|c|}{ Un-standardized Coefficients } & \multirow{2}{*}{\begin{tabular}{|l} 
Standardized \\
Coefficients
\end{tabular}} & \multirow[b]{2}{*}{$\mathbf{t}$} & \multirow[b]{2}{*}{ Sig. } \\
\hline & & B & Std. Error & & & \\
\hline \multirow[t]{2}{*}{1} & (Constant) & 1.226 & .165 & & 7.429 & .000 \\
\hline & $\begin{array}{l}\text { Lost much sleep due to } \\
\text { worry }\end{array}$ & .627 & .053 & -.694 & 11.742 & .000 \\
\hline
\end{tabular}

a. Dependent Variable: Doctors' Performance

The Beta value is -69.4 percent which means that one unit change in job stress will bring about 69.4 unit changes in doctors' performance at public hospitals in Peshawar

\section{DISCUSSION}

It has been observed that doctors working at the public hospitals have shown severe job stress that have been caused due to hectic activities and the job complexity and this has brought a great negative shift in the performance of the doctors and the respective medicine filed in the public hospitals. Such studies that were conducted in the Brazil proved that stress is not good sign for the performance of doctors. It was also seen the doctors who were suffering from job stress they were found smoking and drinking excessively. They used these habits to reduce the work load and get rid of the job stress. [13]. On the other hand this present study Doctor's data showed that they were happy with their job much less than as usual as it was a part of their daily life. Because of such working hours they were unable to concentrate on their job. They lost their sleep due to worry less than usual. Adding to this more doctors was of the idea that they felt that they were making decisions and to be playing a significant part in their less than usual. Majority of the doctors said that they were under strain and they were unable to overcome this difficulty in the life. They were under stress 
and they were unable to enjoy their social life. They were in such a position where they were unhappy and depressed with their daily routine. Doctors' had only weekends to enjoy time with their spouse and they were started considering themselves as not worthy person due to their hectic routines. It was found that there was an impact of jobs stress on doctors' performance and it has negative influence means if job stress increases so their performance decreases accordingly.

\section{CONCLUSION}

Many occupations have been observed in the present with a lot of employees suffering from job or work stress at their respective organization. This has been proven by a number of researches done all over the world in various field of life and it has further added their respective impact on the professional and social life. There always some reason behind this tension that causes severe stress among employees. Every field of profession has its own causes and some are similar to others and some are different to other professions. The topic is a current hot issue that needs to be addressed in a serious manner. In this regard a study was conducted in the 3 public hospitals of Peshawar, each hospital was studies by drawing a sample of 50 from each hospitals. Data was collected from different doctors working in different wards. The researcher aim was to find the impact of the job stress on their performance. The researcher distributed total 150 questionnaires through simple random sampling.

After the analysis done by the researcher, it was concluded that doctors used to get after work calls from the hospitals frequently. Average work hours of majority of the doctors lie in the 31 to 50 hours per week, some also found to have more than 90 hours per week but it depended on the seniority of the doctor, the more the senior the more average hours of work per week. Doctor's data showed that they were happy with their job much less than as usual as it was a part of their daily life. Because of such working hours they were unable to concentrate on their job. They lost their sleep due to worry less than usual. Adding to this more doctors was of the idea that they felt that they were making decisions and to be playing a significant part in their less than usual. Majority of the doctors said that they were under strain and they were unable to overcome this difficulty in the life. They were under stress and they were unable to enjoy their social life. They were in such a position where they were unhappy and depressed with their daily routine. Doctors' had only weekends to enjoy time with their spouse and they were started considering themselves as not worthy person due to their hectic routines. After running the regression test it was found that there was an impact of jobs stress on doctors' performance and it has negative influence means if job stress increases so their performance decreases accordingly. Therefore $\mathrm{H} 1$ hypothesis was accepted and $\mathrm{HO}$ was rejected.

\section{RECOMMENDATIONS}

1. The doctors must focus on their work and try to avoid the stress developing stimulus. This can affect their performance negatively.

2. The management of the public hospitals must reduce the stress developing elements which affects the performance of the doctors

3. Doctors need to be given proper time where they can practice their medical activities and give equal time to their spouse.

4. Doctors' work must be appreciated by the hospital management and such incentives should be given to them so they feel worthy and motivated. 


\section{REFERENCES}

1. Burke, RJ. \&Richardson, AM., 1991. Sources of satisfaction and stress among Canadian physicians. Psychol Rep, 67, pp. 1335-1344.

2. Chambers, R., 1992. The health and lifestyle of general practitioners and teachers. Occupational Medicine, 42, pp. 69-78.

3. Cooper, C.L., Rout, U. \&Faragher, B., 1989. Mental health, Job Satisfaction, and Job Stress among general practitioners. British Medical Journal, 298, pp. 366-370.

4. Gianakos, Irene. 2001. Gender Roles and Coping with work stress. Sex Roles. A Journal of Research (6), pp. 1-13.

5. Hirak, Dasgupta\& Suresh, Kumar. 2009.Role Stress among Doctors Working in a Government Hospital in Shimla (India). European Journal of Social Sciences 9 (3), pp. 356-370.

6. Hussain. 2001. Perceived Stress Effects and Psychological Well-being among Doctors. Stress Research and Stress Management, 1, pp. 37-58.

7. Hussain,Akbar. \&Singh, Karuna. 2001. Perceived Stress Effects among Doctors Exposed to Surgical Source of Stress, 1, pp. 1- 13.

8. McNamee, R., Keen, RI. Corkill, CM. 1987. Morbidity and early retirement among anesthetists and other specialties. BMJ Anaesthesia, 42: 133-140.

9. Chambers, R., 1992. The health and lifestyle of general practitioners and teachers. Occupational Medicine, 42, pp. 69-78.

10. Porter, A.M.D., Howie, J.G.R., \& Levinson, A., 1985. Measurement of stress as it affects the work of the general practitioner. Family Practice, 2, pp. 136-146.

11. Ramirez, AJ. Graham, J., Richards, AC., \& Gregory, WM., 1996. Mental health of hospital consultants: the effect of stress and satisfaction, The Lancet 347 (3), pp.724-728.

12. Rees, D. W., \& Cooper, C.K., 1992. Occupational stress in health service workers in the UK. Stress Medicine, 8, (2), pp. 79-90.

13. Firth-Cozens J. Doctors, their wellbeing, and their stress. BMJ 2003 Mar 29; 326:670-671

14. Wong JGWS, Patil NG, Beh SL, Cheung EPT, Wong V, Chan LC, et al. 2005 Cultivating psychological well-being in Hong Kong's future doctors. Medical Teacher; 27(8): 715-719.

15. Lazarus R, Folkman S. 1984 Stress, appraisal and coping. New York: Springer;

16. Maslach C, Schaufeli WB, Leiter MP. 2001. Job burnout Annual Review Psychol; 52:397-422.

17. McManus IC, Winder BC, and Gordon D. 2002. The causal links between stress and burnout in a longitudinal study of UK doctors. The Lancet; 359: 2089-2090.

18. Crane M. 1998. Why burned-out doctors get sued more often. Medical Economics; 75(10): 210-215.

19. The Royal College of Psychiatrists. The mental health of students in higher education. London: The Royal College of Psychiatrists; 2003. Program for Effective Transition and Student Support [Online]. Available from URL: http://www.hku.hk/facmed/imhse/core5.html 